\title{
MALE INFERTILITY STATUS IN BANGLADESH: ARE WE AWARE ?
}

Infertility and problems of impaired fecundity have been a concern through ages and is also a significant clinical problem today, which affects $8-12 \%$ of couples worldwide [1]. Infertility remains a neglected issue in reproductive health policy of Bangladesh, instead the emphasis has always been on the problem of overpopulation. In developing countries patterns of male infertility are quite different from those in developed countries and incidence of preventable causes are much higher in developing countries[2] . The exact rates of male infertility from developing countries like ours are difficult to find because of the problem with the definition of male infertility and lack of accurate reporting. In recent decades, infertility has impacted an increasing number of couples. Moreover, the fertility rate in men younger than age 30 years has also decreased worldwide by $15 \%[3,4]$. As per the WHO estimates 60-80 million couples worldwide currently suffer from infertility[5]. There are about three millions of couple in Bangladesh who are suffering from infertility. Infertility may be considered as socio-economic problem in Bangladesh because infertility causes family unrest, divorce, multiple marriages and even sometimes suicide. Unfortunately like other developing countries wives are usually blamed for infertility although $60 \%$ cases male are responsible for the problem[6].

So, it is the right time to look into the factors which are causing such a rise in male infertility and attempts should be made to control such factors. Therefore, awareness programme may help addressing this issue.

Bangladesh J. Urol. 2016; 19(1): 1-2

\section{Md. Abul Hossain}

Assistant Editor

Editorial Board

Bangladesh Journal of Urology

\section{References:}

1. Naina Kumar and Amit Kant Singh. Trends of male factor infertility, an important cause of infertility: A review of literature ; J Hum Reprod Sci. 2015 OctDec; 8(4): 191-196.

2. Bashed MA. Male Infertility. Bangladesh Institute ofMedical Sceince (BIMS), Dhaka, Bangldesh. http://www.bims-bd.com/male_inretility.

3. Stephen EH, Chandra A. Declining estimates of infertility in the United States: 1982-2002. Fertil Steril. 2006;86:516-23. [PubMed] 
4. Martin JA, Hamilton BE, Sutton PD, Ventura SJ, Menacker F, Kirmeyer S. Births: Final data for 2004. Natl Vital Stat Rep. 2006;55:1-101. [PubMed]

5. Calverton, Maryland, USA: ORC Macro and the World Health Organization; 2004. World Health Organization. Infecundity, Infertility, and
Childlessness in Developing Countries. DHS Comparative Reports No 9.

6. Bashed MA,Alam GM, Kabir MA and Amin AQA. Male Infertility in Bangladesh: What Serve Better Pharmacological help or Awareness programme? Int.J. Pharmacol., 8(8):687-694;2012. 